\title{
A representância do passado histórico em Paul Ricoeur: linguagem, narrativa, verdade ${ }^{*}$
}

\author{
The "representance" of historical past in Paul Ricoeur: language, \\ narrative, truth
}

\author{
Breno Mendes \\ mendes.breno@gmail.com \\ Doutorando \\ Universidade Federal de Minas Gerais \\ Avenida Paraná, 466/509 - Centro \\ 30120-020 - Belo Horizonte - MG \\ Brasil
}

\section{Resumo}

A representação do passado histórico na obra de Paul Ricoeur é o objeto desse artigo. O caminho escolhido para a investigação passa por conceitos correlatos ao tema, como linguagem, narrativa e verdade. Delinearemos de maneira mais precisa os contornos da representação historiadora em Ricoeur, sobretudo, a partir do neologismo representância, cunhado pelo filósofo, além de considerarmos a recepção de sua teoria entre alguns historiadores. Por fim, em nossas considerações finais, analisaremos as implicações dessa reflexão na noção de verdade histórica.

\section{Palavras-chave}

88

Paul Ricoeur; Representação; Narrativa Historiográfica.

\begin{abstract}
The representation of the historical past in the work of Paul Ricoeur is the subject of this article. The way chosen for the investigation involves concepts related to the theme, such as language, narrative and truth. We will delineate more accurately the contours of historian representation in Ricoeur, mainly from representance neologism, created by the philosopher, in addition to considering the reception of his theory among some historians. Finally, in our concluding remarks, we will analyse the consequences of this reflections on the historical notion of truth.
\end{abstract}

\section{Keywords}

Paul Ricoeur; Representation; Historiographic narrative.

Recebido em: 21/4/2015

Aprovado em: 22/12/2015

\footnotetext{
* Nesse artigo sintetizo alguns argumentos trabalhados em minha dissertação de mestrado sobre Paul Ricoeur. Bolsista do CAPES/PROEX.
} 
No presente artigo pretendemos dissecar a interpretação de Paul Ricoeur sobre a operação de representação do passado histórico. Ressaltaremos as contribuições trazidas pela representância ricoeuriana às relações entre a representação e seu referente e também esquadrinharemos algumas críticas feitas ao filósofo, bem como suas respostas a elas. Nosso trabalho versará sobre a representação no registro da teoria da história. Conforme Falcon, esse conceito-chave do discurso histórico aponta, concomitantemente, tanto para a relação cognitiva mantida pelo conhecimento histórico em relação à realidade, quanto para o caráter linguístico da escrita da história. Dessa forma, uma reflexão sobre a representação do passado envolve pensar as condições de possibilidade do saber histórico como disciplina específica (FALCON 2000).

Um breve olhar sobre a etimologia do termo revela que representação deriva da forma latina repraesentare, cujos significados são: apresentar de novo e tornar presente alguém ou alguma coisa ausente por intermédio de um objeto. Outros sentidos catalogados são: colocar um objeto no lugar de outro e encenar um acontecimento re-apresentando-o no presente. No âmbito político e diplomático, temos a acepção da representação como a prática em que uma pessoa está presente no lugar de outra, substituindo-a e agindo em seu nome como legítima representante. A moderna teoria do conhecimento tende a entender a representação como uma objetivação do mundo exterior à consciência do sujeito cognoscente através de uma imagem ou símbolo que vale por ele (FALCON 2000). Ainda na seara semântica e etimológica, é significativa a distinção feita na língua alemã entre a Darstellung ${ }^{1}$ (apresentação) e a Vertretung (representação/representância). Segundo Pitkin, darstellen é retratar ou colocar alguma coisa no lugar de algo, ao passo que vertreten é atuar como um agente para alguém (PITKIN 2006).

\section{A representação historiadora sob o signo da representância}

As últimas páginas das meditações ricoeurianas sobre a operação historiográfica em A memória, a história, o esquecimento² (2000) se defrontam com o cerne de nosso problema central, a representação do passado. Desde Tempo e narrativa (RICOUER 1983-1985, 3v.), Ricoeur mobiliza o termo representância para buscar compreender a realidade do passado histórico. $\mathrm{Na}$ obra publicada em 2000, ele assinala que essa questão não se restringe aos confins da epistemologia e se coloca no limiar de uma ontologia da existência histórica, chamada de condição histórica:

A palavra "representância" condensa em si todas as expectativas, todas as exigências e todas as aporias ligadas ao que chamamos em outro momento de intenção ou intencionalidade histórica: ela designa a expectativa ligada

\footnotetext{
${ }^{1}$ Ao longo do texto iremos manter, sempre que possível, as menções aos termos originais. Nosso objetivo é apenas deixar explícito qual a opção de tradução estamos endossando. O conceito de Darstelllung, por exemplo, já foi vertido como representação, escolha com a qual não estamos de acordo. Além disso, o fato do conceito original constar entre parênteses permite ao leitor realizar traduções distintas da nossa, caso julgue necessário. 2 Para tornar as referências às obras de Ricoeur mais dinâmicas adotamos o seguinte sistema de abreviaturas: MHE: A memória, a história, o esquecimento; MV: A metáfora viva; T\&N: Tempo e narrativa. As referências completas encontram-se no fim do artigo.
} 
ao conhecimento histórico das construções que constituem reconstruções do curso passado dos acontecimentos (RICOUER 2000b, p. 359).

Ademais, a representância é apontada por alguns comentadores como fulcral para o realismo crítico da epistemologia da história ricoeuriana, situada entre um realismo de objeto e o relativismo. Para Olivier Mongin, Ricoeur prefere falar em representância em lugar de representação para dar conta da especificidade da referência ou do entrecruzamento entre a história e a realidade. Tal abordagem teria alguns pressupostos. O primeiro é que a realidade histórica é um vestígio (trace), pois nosso acesso ao passado não é feito senão pela mediação de um testemunho ou outra fonte documental. O segundo aponta para o ter-sido (avoir été), sempre considerado como o contraponto das reconstruções historiadoras (MONGIN 1994). Johan Michel defende que a representância permite a Ricoeur escapar aos extremos, seja do realismo ingênuo, seja do relativismo, ao apostar na possibilidade de a historiografia cumprir seu voto de representar o passado histórico com fidelidade (MICHEL 2006). ${ }^{3}$

A fase da representação da operação historiográfica concentra algumas das mais obstinadas dificuldades concernentes à referência ao passado (RICOEUR 2000). Por alguns instantes, pode parecer que o historiador não conseguirá cumprir sua promessa de representar o passado adequadamente. Quanto a isso, Ricoeur faz questão de elucidar que essa suspeita não deve se assentar somente no momento da representação escrita, mas também em sua articulação com os

90 níveis anteriores - a explicação/compreensão e a pesquisa documental -, assim como na relação da história com a memória (RICOUER 2000b).

Grande parte das dificuldades ocorre porque a linguagem não é um medium transparente ou alguma espécie de espelho da realidade. Pelo contrário, Ricoeur situa a linguagem no fundamento do conhecimento histórico. Esse gesto implica considerar a inteligibilidade própria ao discurso figurativo da narrativa. $\mathrm{Na}$ epistemologia ricoeuriana, a atenção aos procedimentos formais, contudo, não redundam em um enclausuramento da intriga em si mesma; o ato de narrar não perde seu vínculo com o real.

\section{Representação e referência}

Um bom contraponto à posição ricoeuriana pode ser encontrado em Ankersmit. Em um artigo sobre a natureza da representação histórica, o autor parece ter arrefecido seus ímpetos pós-modernos, conquanto não ofereça uma resposta definitiva no que tange à referência da narrativa historiográfica. A primeira distinção que Ankersmit julga pertinente é entre descrição e representação. A primeira se dá no nível das frases e possui uma referência explícita, na medida em que opera uma identificação única e bem definida na realidade. Exemplos disso seriam nomes próprios como Luís XIV, ou frases do tipo "o homem que pisou pela primeira vez na lua", pois apresentam um 
referente inequívoco. O mesmo não ocorreria com as representações que são formadas por um conjunto de frases. Numa obra sobre a Revolução Francesa, por exemplo, seria quase impossível diferenciar aqueles parágrafos que se remetem exclusivamente ao processo revolucionário daqueles que contêm uma construção de sentido, conferindo uma determinada propriedade aos eventos. Por isso, no juízo desse autor, não seria possível falar de verdade ou falsidade no nível das representações históricas (ANKERSMIT 2012).

Um embaraço apontado pelo historiador holandês acontece quando temos várias representações - às vezes opostas entre si - da mesma pessoa ou acontecimento. Nesses casos, o representado também deveria diferir, uma vez que ele é aquilo que é pintado e delineado por uma representação. O representado não poderia ser tomado como um modelo que está diante do autor, uma vez que cada representação apresenta apenas um aspecto da pessoa ou acontecimento, e não sua integralidade. Para Ankersmit, a representação histórica tem a mesma estrutura da metáfora. Quando criamos conceitos como Renascimento ou Século das Luzes, convidamos o leitor a ver certa parte do passado nos termos daquelas ideias que associamos a essas palavras. No entanto, se a metáfora propõe uma interação entre sentidos e não entre suas referências, no caso da representação histórica, a interação de sentido não exclui da relação parte do próprio passado: "Assim, a interação de sentido existe, mas seu significado se move em uma única direção, ou seja, da linguagem para o mundo. O passado em si é o recipiente mais ou menos passivo do significado" (ANKERSMIT 2012, p. 197).

Apesar de dizer que a relação da linguagem com o mundo não é rompida, a teoria da representação de Ankersmit, a nosso ver, é oscilante. Para ele, conceitos como Renascimento ou Iluminismo têm uma existência apenas discursiva para nos ajudar a organizar o conhecimento sobre o passado. Sob essa ótica, a representação, ao contrário da descrição, não faz referência a coisas individuais na realidade. As consequências disso agravam-se quando o holandês constata que "na representação não podemos chegar da verdade à referência e vice-versa" (ANKERSMIT 2012, p. 219). Em sua distinção, a representação não produz enunciados verificáveis, portanto, não está sujeita à lógica da verdade e falsidade. Algumas páginas adiante, o autor sugere que o nível representativo, além de possuir certa autonomia em relação ao enunciado verdadeiro, teria até uma prioridade sobre ele. Isso pode ser constatado no ambíguo trecho a seguir:

A representação é um preparado mais forte que a verdade. A representação contém a verdade - pense nas afirmações contidas por uma representação histórica - não está contra, mas além da verdade. A representação contém a verdade, mas também pode fazer algo com ela. [...] A representação pode brindar-nos com uma perspectiva sobre o mundo convidando-nos a certo tipo de ação (ANKERSMIT 2012, p. 223, grifos do original). 
Nossa escolha por expor alguns pontos da teoria de Ankersmit ${ }^{4}$ como contraponto não foi aleatória ou acidental. O próprio Ricoeur, em $A$ memória, a história, o esquecimento, já havia examinado e feito algumas críticas a esse autor por conta de teses semelhantes que vêm sendo por ele sustentadas desde Narrative Logic: a Semantic Analysis of the Historian's Language, de 1983. No artigo "Filosofias críticas da história", o filósofo francês identifica na epistemologia de Ankersmit uma firme recusa do realismo e a defesa de um idealismo narrativo, na medida em que, para o holandês, a representação (então chamada por ele de narratios) tem uma certa autonomia em relação aos enunciados pontuais (frases), que podem ser falseáveis. ${ }^{5}$ Contudo, Ricoeur nota, espantado, que as palavras "passado" e "representação" persistem no discurso de Ankersmit. Uma objeção formulada por Ricoeur é que as representações não estariam tão dissociadas assim dos enunciados pontuais a ponto de perder sua ancoragem em fatos verificáveis. A possibilidade de falseabilidade e verificação da fase documental são reafirmadas por Ricoeur, ainda que estejamos diante de narrativas díspares sobre um acontecimento ou pessoa. O fato de Napoleão, por exemplo, ter se tornado uma espécie de personagem controverso de narrativas históricas tão distintas "aboliria o valor referencial do personagem histórico atestado pelos documentos?" (RICOEUR 1994b, p. 181, grifo nosso).

A incomensurabilidade entre as narrativas diferentes sobre o mesmo assunto, sustentada por Ankersmit, é repelida por Ricoeur. Equilibrando-se em uma corda bamba, o filósofo evita cair seja no substancialismo, seja no relativismo, ao dizer que fora da cronologia e de uma certa crônica-esqueleto das ações que sustenta as interpretações não temos nada que nos garanta o fato de duas histórias estarem falando da mesma coisa. Porém, esses dois elementos asseguram a junção entre o nível dos enunciados pontuais e o da interpretação global, ou representação. Além do mais, Ricoeur recomenda levarmos em conta a recepção dos textos, que estabelece interseções entre as narrativas, frisando o conteúdo que elas teriam em comum. Afinal, não podemos nos esquecer de que

\footnotetext{
${ }^{4}$ Sem dúvida, a leitura que fizemos de Ankersmit é pontual, limitada e orientada pela nossa hipótese central. Entretanto, nossa intenção não foi desqualificar a posição do historiador holandês, que tem contribuído bastante para as discussões de Teoria da História. Vale lembrar que a relação entre Ankersmit e Ricoeur é ambivalente e não se pauta, estritamente, por um antagonismo. Na obra História e tropologia (1994), Ankersmit afirmou o seguinte sobre Tempo e narrativa: "Talvez, nenhum livro no campo da filosofia da história, desde a Segunda Guerra Mundial, traga maior riqueza de aprendizagem e uma avaliação imparcial do que se tem feito até agora, ou um maior talento para sintetizar tradições distintas e heterogêneas" (ANKERSMIT, 2004, p. 137). No entanto, um pouco adiante, ele lamenta que o filósofo francês tenha regressado da tradição narrativista para a tradição epistemológica ao não se deter apenas em questões linguísticas, mas também se preocupar com a relação que os enunciados mantêm com a realidade do passado histórico. É necessário destacar, ainda, que o próprio Ankersmit afirmou ter abandonado a ênfase na tradição narrativa e se voltado para o tema da representação. "Segue-se uma discussão acerca da narrativa não lançará nenhuma luz sobre o problema da verdade histórica, considerando que a narrativa está principalmente associada ao romance. É por isso que passei, há algum tempo, da noção de narrativa para a de representação. Em primeiro lugar, porque essa noção não está contaminada com tudo que os narrativistas associam com a narrativa; e, em segundo lugar, porque a noção sugere forte -mente o que é representado: se você tem representações também deve haver algo que é representado por elas. Deste modo você pode corrigir o distanciamento entre linguagem/realidade, tão característico da teoria narrativista" (ANKERSMIT 2012, p. 321).

${ }^{5}$ No artigo Representação e referência, Ankersmit parece manter esse posicionamento, pois para ele o passado é semelhante a uma tela em branco na qual o historiador projeta significados com sua representação. "Nós os projetamos no mundo - ao projetar o significado sobre o passado, como metáfora histórica e repre -sentação. Não nos perguntamos se, dado um determinado sistema teórico ou estilo, o pintor representou corretamente parte do mundo. Este é o tipo de pergunta que pertence às ciências, e não à arte (ou a história da arte). Não é a verdade, mas sim o estilo que conta" (ANKERSMIT 2012, p. 200).
} 
uma teoria da escrita está incompleta caso desconsidere uma teoria da leitura. Isso não equivale a subsumir duas narrativas que tratam do mesmo assunto sob um único e homogêneo gênero. Como raramente um historiador é o primeiro a tratar de um dado período ou escola de pensamento, ele sempre buscará, de alguma forma, corrigir ou modificar o que seus predecessores disseram sobre o mesmo tema. Portanto, há uma crença subentendida de que estão falando da mesma coisa:

Podemos conceder que esta identidade é uma identidade fluida (floue), e que se pode dizer, sem paradoxo, que a Revolução Francesa, segundo Furet tem poucas coisas em comum com a Revolução Francesa segundo Michelet. No entanto, são essas poucas coisas que salvam a identidade fluida de denominação (RICOEUR 1994b, p. 184, grifos do original).

A suspeita contra a referencialidade da representação lançada por Ankersmit ${ }^{6}$ suscita nos historiadores, segundo Ricoeur, uma veemente réplica, que transforma em protesto a atestação da realidade que o historiador atribui a uma boa obra histórica. Esse grito pode se aproximar de forma surpreendente do adágio rankeano que propõe narrar os acontecimentos tal como ocorreram realmente. Entretanto, pergunta-se Ricoeur, como evitar que esse movimento conduza a uma ingenuidade epistemológica? Sua resposta: se os modos representativos que supostamente dão forma literária à intencionalidade histórica são questionados, a única maneira de atestar a realidade é recolocar em seu lugar a fase escriturária em relação à explicação/compreensão e a fase documental: "Juntas, escrituralidade, explicação compreensiva e prova documental são suscetíveis de credenciar a pretensão verdade do discurso histórico" (RICOUER 2000b, p. 363). Isso significa que é preciso remeter a arte da escrita da história às técnicas de pesquisa e aos procedimentos críticos que podem trazer o protesto (narrar tal como aconteceu) à forma de atestação transformada em crítica.

Diante da provocação escrita pelo autor Roland Barthes, para quem "o fato não tem senão uma existência linguística" (BARTHES 2004), Ricoeur chega até a indagar se ele próprio não teria sucumbido a essa ideia, ao distinguir, como já vimos anteriormente, o fato (construído com sólida investigação documental e mediação

\footnotetext{
${ }^{6}$ No texto História e verdade para além da virada linguística: a contribuição de Ankersmit, o autor oferece uma leitura diferente da nossa. Para Silva, Ankermit tem buscado lutado contra seu "calcanhar de Aquiles" o relativismo radical. "Cremos ser possível afirmar, a título de conclusão, que os argumentos de Ankersmit em A escrita da História contribuem para tornar os historiadores menos cautelosos em face da Virada Linguística, pois o autor, ao definir a explicação histórica como uma modalidade de representação do passado mediada pela linguagem, não nega a possibilidade de que haja representações mais ou menos plausíveis - alguns talvez preferissem dizer mais ou menos "verdadeiras" -, opondo-se assim a um relativismo radical que, ao insistir sobre o caráter ficcional das narrativas históricas, termina por introduzir o irracionalismo na "oficina" dos historiadores, algo que Ankersmit se nega a admitir. (SILVA 2014, p. 186)

7 O crítico literário francês assemelhou a história-narrativa de Fustel de Coulanges ao romance realista oi -tocentista. Os dois escreveriam textos em que o enunciador parece estar ausente e a história se desenrola objetivamente, sem a intervenção do autor; "a história parece contar-se sozinha" (BARTHES 2004, p. 169). Nessas narrativas, em que há uma carência dos signos do enunciante, haveria aquilo que ficou consagrado como a "ilusão referencial". Sua polêmica tese, que ainda nos dias atuais causa espanto e perturbação em meio aos historiadores: "O fato nunca tem mais do que uma existência linguística (como termo de um discur -so), e, no entanto, tudo se passa como se essa existência não fosse senão a "cópia" pura e simples de uma outra existência, situada num campo extraestrutural, o "real". Esse discurso [o histórico] é, sem dúvida, o único em que o referente visado como exterior ao discurso, sem que nunca seja, entretanto, possível atingi-lo fora do discurso (BARTHES 2004, p. 177)
} 
linguística) do acontecimento. Todavia, nas palavras do próprio filósofo, "o realismo crítico aqui professado" (RICOUER 2000b, p. 364) o leva para um passo aquém da proposição factual, ao invocar a dimensão testemunhal do documento. No coração da prova documental estaria a tríplice declaração da testemunha de que: 1) estava lá; 2) acreditem em mim; 3) se não acreditarem, perguntem a outrem. Caçoar do realismo do testemunho, salienta Ricoeur, é negligenciar o germe da crítica que ele traz: "Ocorreu-me dizer que não temos nada melhor do que a memória para assegurar a realidade de nossas lembranças. Agora, dizemos: não temos nada melhor do que o testemunho e a crítica do testemunho para dar crédito (accréditer) à representação historiadora do passado" (RICOUER 2000b, p. 364).

\section{Representação e verdade}

Antes de chegar ao seu limiar, a senda ricoeuriana pela representação historiadora defronta-se com o problema da verdade, engendrando a pergunta: o que a discussão sobre a verdade poderia acrescentar ao conceito de representância? A grande dúvida consiste em saber até que ponto existe a possibilidade de adequação e correspondência, uma vez que o passado, objeto referencial da pretensão veritativa, é o "ausente da história", e a linguagem não é um meio transparente de reprodução. Desde Tempo e narrativa, Ricoeur tem defendido que a representação histórica tem no passado sua contraparte (vis-à-vis). Nessa ocasião, a ideia de lugar-tenência era empregada para precisar o modo de verdade próprio da representância, a ponto de o autor quase considerá-las como sinônimas. Entretanto, a questão não é resolvida de forma tão simples. O mais prudente é especificar quais aspectos da noção de correspondência ficam excluídos do processo (RICOUER 2000b).

A imitação-cópia é o primeiro aspecto da correspondência que é descartado: "Uma narrativa não se parece com o acontecimento que ela narra" (RICOUER 2000b, p. 366). Uma heterologia mínima entre a representação e seu referente subjaz à própria noção aristotélica de mímesis, na qual a ricoeuriana está fundamentada, como produtora de sentidos para os acontecimentos. Sob a batuta dos três momentos da mímesis, a prefiguração, a configuração e a refiguração, acentua-se a distância entre a mímesis ricoeuriana e a imitação-cópia. Em 1998, no texto "A marca do passado", Ricoeur havia proposto que a dimensão fiduciária do testemunho substituísse o enigma da relação de semelhança: "É preciso deixar de se perguntar se uma narrativa se assemelha a um acontecimento para se perguntar se o conjunto de testemunhos, confrontados entre si, é fiável" (RICOEUR 2012, p. 334). Todavia, essa troca de problemáticas não pode se consumar até as últimas consequências. Dois anos depois, em A memória, a história, o esquecimento, Ricoeur prefere ser um pouco mais cauteloso: "Convém dizer que nunca se acaba totalmente com esse fantasma, na medida em que a ideia de semelhança parece difícil de expulsar totalmente" (RICOUER 2000b, p. 365).

O segundo aspecto da correspondência a ser discutido é o de adequação, que contribui para a elaboração, no terceiro tomo de Tempo e narrativa, do conceito de representância. No entanto, naquela época, o filósofo nutria grandes expectativas em relação à dialética dos grandes gêneros Mesmo, Outro 
e Análogo. ${ }^{8}$ Tal posição foi repensada pelo autor e tomou novos rumos, tendo como norte o crivo testemunhal:

A representância, posso dizer, exprime a opaca mistura entre a lembrança e a ficção na reconstrução do passado. Pelas mesmas razões, espero, hoje, menos luzes do que outrora da dialética entre o mesmo, o outro e o análogo, por meio da qual eu tentava articular conceitualmente a relação de representância. Este recurso à analogia, para além da oposição entre o mesmo e o outro, parece-me, atualmente, excessivamente tributária da problemática da eikôn, talvez por não ter passado pelo crivo do testemunho (RICOEUR 2012, p. 336).

O propósito disso, segundo Ricoeur, é tentar salvar o que deve ser retido da fórmula de Ranke, segundo a qual a tarefa da história não é julgar os acontecimentos do passado, mas mostrar os acontecimentos tais como eles efetivamente ocorreram. Nesse sentido, o "tal como" da fórmula designaria apenas a função de lugar-tenência; "O que 'realmente' se passou continua assim inseparável do 'tal como' efetivamente se passou" (RICOUER 2000b, p. 366). De modo análogo a de Certeau, Ricoeur pensa que o discurso histórico implica uma relação com o outro enquanto ele está ausente (CERTEAU 2012). A especificidade da historiografia reside no fato de este ausente carregar a marca da anterioridade presente no passado. Nessa perspectiva, o discurso histórico transforma a diferença em seu objeto. O ponto de partida ocorre quando uma sociedade se define ao distinguir-se do seu outro, chamando-o de passado. Assim, outorga-se à história a incumbência de investigar as regiões exteriores à circunscrição do presente. A escrita, aliada às práticas e ao lugar social, constitui o empreendimento de compreensão no qual o presente busca tornar a alteridade do passado assimilável e compreensível (CERTEAU 2007). Segundo Certeau, o estatuto social do historiador o coloca em uma posição ambivalente: por um lado, ele fica incumbido de explicar a estranheza, ainda que sem suprimi-la completamente; por outro, ele deve buscar semelhanças onde se apresentam as dessemelhanças, para que esse estudo traga alguma contribuição para o tempo presente. A escrita da história se mostra como "um discurso que organiza uma presença faltante" (CERTEAU 2012, p. 188).

\section{A recepção da teoria da representação ricoeuriana pelos historiadores}

Roger Chartier é um dos entusiastas da teoria da representação ricoeuriana. Para esse historiador cultural, a obra de Ricoeur é aquela que mais dedicou atenção aos modos de representação do passado, seja pela narrativa histórica, pelo discurso ficcional ou pelas operações da memória. O principal mérito destacado por Chartier seriam os subsídios fornecidos pelo filósofo em tempos de relativismo para proteger as possibilidades de o discurso histórico ser uma representação e explicação adequadas da realidade do que um dia aconteceu. Nas conclusões de seu artigo "Defesa e ilustração da noção de representação", o historiador francês

${ }^{8}$ A dialética entre o Mesmo, o Outro e o Análogo foi apresentada no terceiro capítulo do terceiro volume de Tempo e narrativa. 
subscreve a recomendação ricoeuriana de remeter a fase da escrita aos outros momentos da operação historiográfica, à explicação/compreensão e à crítica documental. Somente por essa via, a atestação poderia prevalecer contra a dúvida de não pertinência da representação historiadora (CHARTIER 2011).

Porém, nem sempre a recepção ricoeuriana entre os historiadores franceses foi amistosa. No dossiê organizado em 2002 pelo periódico Le débat, por conta da publicação de $A$ memória, a história, o esquecimento, o texto de Alexandre Escudier $^{9}$ sobressai pelas contundentes críticas à teoria da representação ricoeuriana. O primeiro questionamento se dirige à homogeneidade que, segundo esse autor, é estabelecida por Ricoeur entre a representação do passado, a representação mnemônica, as representações sociais e a representação historiadora como componente da escrita histórica. Outro ponto levantado incide sobre a escolha ricoeuriana pelo termo Vertretung - representância, lugar-tenência - para qualificar a narrativa histórica. Essa opção, na interpretação de Escudier, marca um distanciamento do filósofo em relação aos historiadores de métier, já que, desde o século XVIII, a noção empregada por eles para designar as exposições das pesquisas históricas é Darstellung ${ }^{10}$ [apresentação/exposição] ou mesmo Darglegung [presentificação, mostração] (ESCUDIER 2002).

Outro alvo dos ataques do crítico é a dialética apontada por Ricoeur entre a representação/objeto e a representação/operação. Ora, na visão de Escudier, o filósofo francês agiu de maneira ilícita, porque normativa, ao colocar as representações sociais como campo privilegiado das investigações históricas. Aliado a isso estaria o procedimento de instituir o vínculo social e a construção de identidades como objetos pertinentes do discurso histórico. Entretanto, como ressalta Escudier, atualmente nada pode ser colocado como objeto privilegiado das análises históricas. O domínio dos objetos da história já não está mais restrito a apenas alguns aspectos do passado. A curiosidade do historiador pode se dirigir, em princípio, a tudo aquilo que pode ser localizado em um determinado instante temporal e espacial. Para nós, essa objeção é pertinente, sobretudo, porque acreditamos que uma relação saudável com a história da historiografia não deve universalizar ou generalizar as práticas de uma determinada comunidade historiográfica: "Colocar as modalidades de constituição do vínculo social e os problemas de identidade a ele ligados como constituindo 'o objeto pertinente do discurso histórico' é delimitar o domínio dos objetos de história a partir de uma escolha de valores heterogêneos à ciência" (ESCUDIER 2002, p. 20).

Para além do fogo cruzado da crítica, Escudier também trouxe relevantes esclarecimentos para a compreensão da representação historiadora em Ricoeur.

\footnotetext{
${ }_{9}^{9}$ Trata-se de um historiador francês especialista em teoria da história na Alemanha do século XIX, notadamente, em temas ligados ao historicismo, hermenêutica e metodologia da história. Também atua como tradutor de obras alemãs para o francês com destaque para Précis de theorie de I'histoire de Droysen e Le concept de I'histoire de Koselleck.

10 Walter Benjamin utilizou esse termo para se referir à escrita filosófica no prefácio epistêmico-crítico de sua Origem do drama barroco alemão (1928). A primeira tradução brasileira da obra feita por Rouanet vertia o termo como representação. Entretanto, J.M. Gagnebin, sustenta enfaticamente que essa opção é equivocada, pois Benjamin buscava escapar da concepção moderna de representação (Vorstellung) como representação mental de um objeto exterior ao sujeito. A autora indica como tradução mais adequada a Darstellung as noções de apresentação e exposição, sendo que o termo também é usado para designar apresentações teatrais (GAGNEBIN 2005).
} 
Quando apresentara inicialmente o conceito de representância em Tempo e narrativa, o filósofo revelou que o havia extraído da obra do historiador alemão Karl Heussi. ${ }^{11} \mathrm{O}$ que Escudier nos mostra é que um dos propósitos de Heussi com essa noção era combater em dois fronts. Em um deles, estaria a vertente objetivista do historicismo e, no outro, um irracionalismo de raiz nietzscheana. Dessa forma, haveria uma rejeição tanto à epistemologia ingênua contida na teoria do reflexo, quanto às dúvidas mais radicais sobre a possibilidade do conhecimento histórico. Para o autor alemão, o passado não é nem algo completamente determinado com a fixidez de uma estrutura, nem, muito menos, algo totalmente conhecível pelo espírito humano. Nesse sentido, a noção de contraparte (vis-à-vis) visa caracterizar o conjunto daquilo que um dia foi ( $a$ été), independentemente do que nós queremos ou podemos conhecer. Nesse quadro, o historiador não pode se aproximar da realidade passada senão aproximativamente (ESCUDIER 2002). Não podemos deixar de apontar as semelhanças dessa postura com o realismo crítico que defendemos estar presente na epistemologia ricoeuriana, na qual também há uma militância contra duas frentes, o realismo ingênuo e o relativismo radical. ${ }^{12}$

A leitura ricoeuriana de Heussi, entretanto, contém um equívoco, sob a ótica de Escudier. Quando o historiador germânico fala de contraparte (vis-à-vis), ele a utiliza como um conceito limite que não tem estatuto metodológico, mas somente funciona como um regulador no nível transcendental das condições de possibilidade do conhecimento histórico. Essas especificações também valeriam para a noção de representâncias (Vertretugens, empregadas sempre no plural por Heussi). A consequência disso, na opinião de Escudier, é que o autor original da ideia, Karl Heussi, jamais teria visado substituir o conceito de apresentação (Darstellung) empregado para as narrativas históricas pelo de representância. Quando Ricoeur tenta tornar esses conceitos operacionalizáveis, ao mobilizá- Ios contra os negacionistas e os excessos pós-modernistas (nomeadamente Ankersmit), ele teria incorrido, por conseguinte, em uma extrapolação abusiva (ESCUDIER 2002).

\section{Repensando a representância}

Após reler seus escritos, em nota de rodapé que encerra a parte II de $A$ memória, a história, o esquecimento, intitulada "História/Epistemologia", Ricoeur reconheceu a noção de representância como a mais problemática de toda essa parte da obra. Antevendo possíveis objeções, o filósofo destacava que essa ideia não é fruto de uma improvisação, mas traz consigo uma longa história semântica. Seu ancestral mais longínquo seria a repraesentatio romana, que indica a suplência legal exercida pelos 'representantes' visíveis de uma autoridade 'representada'. O suplente consegue exercer seus direitos, mas sua legitimidade depende da pessoa que ele representa. Hans-Georg Gadamer foi o autor responsável por não

\footnotetext{
${ }_{11}$ A rigor, portanto, o conceito de representância não foi um neologismo cunhado por Ricoeur, mas foi ressig -nificado pelo mesmo.

12 Por relativismo radical entendemos uma postura epistemológica antirrealista que postula não ser possível representar de forma adequada o passado histórico e referir-se a uma realidade extradiscursiva.
} 
apenas empregar o conceito, mas também a sondar suas dimensões ontológicas no contexto de uma hermenêutica da obra de arte, incluída na primeira parte de sua obra magna, Verdade e método (1960) (RICOUER 2000b).

A derradeira objeção de Escudier à epistemologia ricoeuriana que vamos examinar pesa, justamente, sobre a transposição feita do conceito de representação-suplência da esfera estética, como ela é manejada em Gadamer, para os domínios da historiografia. O crítico de Ricoeur manifestou profundo incômodo com essa iniciativa, porque, para ele, esse conceito está muito distante da metodologia histórica e, portanto, diminuiria a autonomia epistêmica do saber histórico. O fato de Ricoeur sustentar que a problemática da representação tem origem não na historiografia, mas na memória e seu anseio de tornar presente uma ausência através da lembrança também foi criticado porque dificultaria o delineamento de uma metodologia plenamente operacional. Em suma, para Escudier, a noção de representância deveria ser abandonada em favor da categoria de "exposição (Darstellung) histórica" (ESCUDIER 2002).

Para sopesarmos as objeções dirigidas à teoria da representação ricoeuriana, iremos nos valer de dois procedimentos: a) explicitaremos suas afinidades com o conceito de representação em Gadamer; b) analisaremos as respostas dadas pelo próprio Ricoeur ao texto de Escudier.

Em Verdade e método, Gadamer propõe os traços fundamentais para uma hermenêutica filosófica que parte da questão da compreensão. Tomando como fio condutor os modos de manifestação e acontecimento da verdade que não estão necessariamente vinculados aos métodos da ciência moderna, a obra está dividida em três grandes partes que tratam dessas questões, respectivamente, na arte, nas ciências do espírito - notadamente a história - e na linguagem. Ao discutir sobre a experiência estética, na primeira parte do tratado, o hermeneuta alemão tematizou a noção de representação nos parágrafos dedicados à valência ontológica da imagem (Bild). Desde logo, cabe ressaltar que Gadamer está se insurgindo contra as análises estéticas que procuram julgar a obra de arte seja a partir das intenções autorais, seja pela referência àquele que a vivencia e toma somente a si próprio para avaliá-la (GADAMER 2011).

Em busca de uma experiência mais originária da obra de arte, Gadamer se lança em uma discussão sobre a representação. Logo de saída, o hermeneuta deixa claro que o mundo representado pela imagem não é uma cópia. A mímesis em jogo nesse processo não designa um ato de copiar, mas a manifestação do representado, sem a qual ele não se faz presente. A relação entre a imagem e seu mundo não pode ser enquadrada nos mesmos parâmetros da ligação entre cópia e original. A tarefa da cópia não é outra senão tentar se igualar à imagem original. Para tanto, ela suspende seu próprio ser e se coloca a serviço do copiado. Ela busca ser uma reprodução cuja única função é a identificação do mesmo. Ela anula a si mesma ao funcionar como um meio, que, assim como todos os meios, perde sua razão de ser quando alcança seu fim (GADAMER 2011).

No caso da imagem (Bild) a situação é bem distinta, segundo Gadamer. Ela não é, de maneira nenhuma, auto-anulada, já que não é um meio para um fim. O que realmente importa é como na imagem se representa o representado, de 
tal forma que a representação está essencialmente vinculada ao representado, inclusive fazendo parte dele. Por isso, a imagem do quadro (Bild) difere da do espelho, que não possui um ser real, mas apenas uma aparência de efêmera existência dependente do reflexo. Não obstante, a representação permanece referida a uma imagem original, que nela vem a ser representada. Porém, ela é mais que uma cópia, e o fato de não ser a própria imagem original não tem nenhuma conotação negativa, mas, pelo contrário, corrobora sua realidade autônoma, no sentido de possuir um ser próprio. Um dos objetivos maiores do filósofo alemão é estabelecer o status ontológico da imagem, que é indissolúvel ao seu mundo (GADAMER 2011).

Ao conferir um ser próprio à imagem, Gadamer possibilita que sua relação com o original não seja unilateral, como ocorre com a cópia. Como envolve um processo ontológico através da representação, o representado experimenta um acréscimo de ser, ou seja, a representação é capaz de extrair e revelar algo do original que não aparece num primeiro olhar. Buscando ser fiéis ao espírito hermenêutico da obra, poderíamos dizer que a imagem envolve uma interpretação e transformação do representado. Contudo, em nenhum momento, a realidade ontológica da imagem deixa de depender do original. Quase no fim de sua exposição sobre esse tema, Gadamer sustentou que a valência ontológica da imagem seria mais bem caracterizada pelo termo latino repraesentatio, que era familiar ao Direito romano e ganhou um novo destaque na doutrina cristã da encarnação:

Representatio já não significa apenas cópia ou representação (Darstellung) plástica [...], mas significa agora 'representação' (Vertretung) (no sentido de ser representante). O termo pode adotar esse significado porque o retratado (Abgebildete) está presente por si mesmo na imitação (Abbild). Representar significa fazer com que algo esteja presente. No conceito jurídico da representação, o importante é que só a persona representata é o apresentado (Dargestellte) e exposto, e que, não obstante, o representante que exerce seus direitos depende dela (GADAMER 2011, p. 202 , nota 252).

Esses argumentos da hermenêutica gadameriana são essenciais, segundo o próprio Ricoeur, para a compreensão de sua tentativa de transposição da representação-suplência dos quadros da estética para a historiografia. O que legitimaria essa conduta seria o componente imagético da lembrança. Para designar o passado, a reminiscência recorre a uma figuração. De modo semelhante, poderíamos afirmar que a narração acrescenta visibilidade àquilo que relata. No entendimento ricoeuriano, isso tornaria possível estender seja à lembrança-imagem, seja à representação-suplência a ideia de acréscimo de ser indicada por Gadamer: "O que é assim aumentado pela representação figurada, é o próprio pertencimento do acontecimento ao passado" (RICOUER 2000b, p. 368, nota c). A contínua reescrita da história, fruto da dimensão crítica do conjunto das operações historiográficas, cooperaria, a cada nova interpretação, para um acréscimo de sentido da realidade pretérita: "A ideia de representância é então a maneira menos ruim de homenagear um procedimento reconstrutivo, o único disponível a serviço da verdade em história" (RICOUER 2000b, p. 369, nota e). 
Para cumprirmos nossa promessa, resta apenas analisarmos as respostas dadas pelo próprio Ricoeur às críticas de Escudier. O primeiro raciocínio do autor é sublinhar que, em que pese à polissemia do conceito de representação, sua obra $A$ memória, a história, o esquecimento pode ser lida como um empreendimento de localização (mise en place) da representação em uma série de contextos. Entretanto, haveria um hipercontexto comum que Escudier não levou em consideração: todas são representações do passado. Como consequência, haveria uma polissemia regrada na dialética da representação. Se não há uma unidade lexical do termo, existe uma coerência de problemática, na medida em que em todas as esferas (memória, representação-objeto; representação-operação; condição histórica) percebe-se uma reivindicação de verdade (RICOEUR 2002).

Quanto à acusação de ter agido de forma normativa, Ricoeur prefere contemporizar. Por ter levado em conta a história econômica, a história política juntamente com a história das representações sociais, ele pensa não ter agido de forma tão imperiosa como a descrita por Escudier. Porém, o filósofo assume sua preferência pela escola francesa pós-braudeliana, principalmente pela obra de Bernard Lepetit, As formas da experiência (1995). Essa eleição seria motivada pela busca de uma ancoragem do discurso histórico na realidade social que possibilitasse a interação com a sociologia da ação, preocupada com os acordos sociais e com as intervenções dos agentes no curso dos acontecimentos: "Essa série de alianças me interessa, sem que eu as atrele a uma pretensão normativa" 100 (RICOEUR 2002, p. 50).

No que diz respeito às observações filológicas de Escudier, a resposta ricoeuriana consiste em marcar sua distância em relação à concepção kantiana da representação (Vorstellung), como uma reprodução mental de um objeto exterior ao sujeito. A representação (Vorstellung) é um componente essencial da revolução copernicana operada por Kant, ao deslocar do objeto para o sujeito aquilo que regula o nosso conhecimento. Assim, os objetos seriam regulados menos por sua natureza do que por nossa faculdade de intuí-los. Para que essas intuições se tornem conhecimentos, é preciso relacioná-las aos objetos dos quais elas são representações. Nos termos do próprio Ricoeur, ele buscou sair do círculo mágico ${ }^{13}$ da Vorstellung kantiana ao recorrer, nos quadros de um realismo crítico, ao par Darstellung, no sentido de exposição, apresentação, e Vertretung, no sentido de representação-vicária. Endossando a hermenêutica gadameriana, Ricoeur acentua a intensidade ontológica do conceito que o retira dos quadros estritamente epistemológicos (RICOEUR 2002).

Em uma de suas últimas obras publicadas em vida, Percurso do reconhecimento (2004), o filósofo francês advertia que, para sair do kantismo, era necessário colocar a experiência de estar-no-mundo como a referência última de todas as experiências particulares. Se conectarmos essa assertiva à hermenêutica da condição histórica, presente em A memória, a história, o 
esquecimento, veremos que, para Ricoeur, fazemos a história e fazemos história porque somos históricos. Historicidade e temporalidade fariam parte de uma condição inultrapassável de nosso ser-no-mundo. Talvez, nos arriscaríamos a dizer, esse também seja um dos motivos pelos quais Ricoeur não utiliza a representação como Vorstellung, e sim como Vertretung. Afinal, como um ser que é histórico poderia realizar uma reprodução mental de algo exterior, ao tentar representar um aspecto da história, na qual, de modo mais amplo, ele também está imerso?

O próximo passo da defesa ricoeuriana marcha na direção de sua apropriação da estética gadameriana. Nesse sentido, Ricoeur salienta que em nenhum momento fez críticas à categoria de Darstellung (apresentação, exposição), o que o leva a questionar Escudier: "onde você viu que eu 'milito contra' o termo em minha nota filológica em que invoco o par Vertretung-Darstellung citando Gadamer?" (RICOEUR 2002, p. 49). Aliás, após uma consulta à edição alemã de Verdade e método, constatamos que, na sua discussão sobre a valência ontológica da imagem, o hermeneuta empregava a noção de Darstellung, que foi traduzida por representação na edição brasileira (e, segundo Ricoeur, também na francesa). Apenas ao comentar sobre as raízes latinas da representação na nota de rodapé que citamos anteriormente, o autor se valeu do termo Vertretung. Para além disso, Ricoeur se esforça para evidenciar que seu empréstimo feito à estética não é determinante em sua avaliação da verdade histórica. Desse modo, a ideia do acréscimo de ser não teria sido mobilizada para dar crédito à representância (RICOEUR 2002).

Um olhar mais detido sobre as palavras ricoeurianas citadas no parágrafo anterior pode elucidar alguns pontos. Primeiramente, Ricoeur, pensando em Gadamer, referiu-se à relação entre Vertretung e Darstellung como um par, e não como a substituição de um pelo outro. Pode ser que para ele, assim como para Jean Ladrière, ${ }^{14}$ a representação, tal como praticada na teoria do conhecimento, repouse sobre uma dupla metáfora: a da representação teatral e a da representação diplomática. A primeira está próxima da acepção da apresentação (Darstellung) e consiste em colocar na presença (mise en présence) do expectador uma situação significativa através de figuras evocadoras e do encadeamento de ações (LADRIÈRE s/d). Parece-nos que esse era o sentido do termo Darstellung na historiografia alemã do século XIX, tal como enunciou Humboldt em sua clássica conferência de 1821: "A tarefa do historiador consiste na exposição (Darstellung) do acontecimento. Tanto maior será seu sucesso quanto mais pura e completa possível for esta exposição" (HUMBOLDT 2010, p. 82). Não era estranho a historiadores do porte de Humboldt, Ranke e Droysen a ideia de que para apresentar os eventos em um relato seria preciso mobilizar a faculdade imaginativa e criativa do sujeito de conhecimento. Contudo, para eles, a discussão sobre a exposição (Darstellung) estava circunscrita aos domínios da narração. Em Ricoeur, com o conceito de representância, a argumentação 
é estendida para outras dimensões da operação historiográfica, atingindo, inclusive, a operação mnemônica.

Por outro lado, Ladrière fala da vicariedade da representação diplomática, com a qual a representância ricoeuriana possui estreitas semelhanças. A primeira funciona a partir de uma transferência de atribuições na qual uma pessoa é autorizada a agir em nome ou lugar de outra, colocando-se como seu lugar-tenente. Escudier, em suas críticas, insiste bastante na necessidade vista por ele de substituir a representância (Vertretung) pela exposição (Darstellung) histórica. Contudo, uma outra possibilidade, insinuada por Ricoeur e Ladrière, fundamenta-se em uma dialética das duas compreensões: "De um lado, a presença efetivamente direta de uma pessoa, de um objeto, de uma ação: e de outro, presença indireta, mediatizada pela primeira, de uma realidade que não pertence ao campo da apreensão direta" (LADRIÈRE s/d, p. 1).

Consoante a essa proposta interpretativa, a representação historiadora operaria em um duplo registro. Sob um aspecto, ela se porta como uma presentificação da ausência do passado, por intermédio da narração das ações e dos signos linguísticos. Sob outro viés, ela se comporta como representante do passado, numa relação de suplência, colocando-se em seu lugar, mas sem deixar de depender de sua existência pretérita:

Esta concorrência e essa complementaridade entre substituição e apresentação (présentation) não anunciam o par (couple ${ }^{15}$ ) Vertretung/ Darstellung? Com efeito, para sair do círculo mágico da Vorstellung kantiana que fomos revalorizar, nos quadros de um realismo crítico, as noções de Darstellung, no sentido de exposição, de exibição, de mostração (monstration), de apresentação, e de Vertretung, no sentido de representação-vicária (como se fala de "representantes do povo") (RICOEUR 2002, p. 48-49).

Os rastros do passado colocam em jogo boa parte das questões ligadas à representação do passado. Os vestígios indicam uma marca que foi deixada pela passagem de um ser. A marca assume a forma de um signo que vale pela passagem e demanda interpretação. Essa significância combina uma relação de causalidade entre a coisa marcante e a coisa marcada, análoga à existente entre o vestígio e a passagem. O rastro, assim como a escrita da história, exerce uma função vicária em relação ao passado. O rastro vale pelo passado na medida em que é seu representante, lugar-tenente. Essa analogia também coloca em evidência o modo indireto da referência ao passado, já que, como uma ciência por rastros, a historiografia não atinge seu referente senão através das mediações. Uma vez mais, Ricoeur insiste na distinção entre sua Vertretung (representância) e a Vorstellung:

A Vorstellung é a imagem mental que um sujeito se dá de algo exterior ausente (Sich vorstellen). A Vertretung é a relação pela qual um representante fica no lugar daquele que ele representa em sua ausência.

${ }^{15}$ A tradução mais corrente dessa palavra é casal, o que pode ser um indício de como Ricoeur vê a relação entre os conceitos Vertretung/Darstellung sob a ótica da complementaridade. 
É o caso do rastro. Enquanto ele foi deixado pelo passado exerce a seu respeito uma relação vicária (RICOEUR 1994b, p. 196).

Os comentadores desdobram importantes implicações da representância ricoeuriana, principalmente colocando-a como um caminho favorável para escapar das armadilhas do relativismo. Gagnebin ressalta que a preocupação do filósofo além da epistemologia também compreende a ética na reconstrução do passado. Em face da Shoah, a historiografia não poderia pender nem para o relativismo nem para o dogmatismo dito positivista. Destarte, o historiador e a escrita de sua representação contribuem para que a realidade do passado traumático não seja relativizada em sua existência, que não pode deixar de ter-sido (GAGNEBIN 2011). Já para Dosse, o principal aporte epistemológico da representância consiste em sua abertura para o referente, numa submissão do discurso histórico àquilo que um dia foi, em uma relação de suplência. Acresce a isso a ambição veritativa da historiografia, que a impede de ser confundida com a ficção (DOSSE 2001b).

Se o par entre Darstellung e Vertretung foi pinçado por Ricoeur da hermenêutica de Gadamer, a relação entre verdade e método vislumbrada pelo autor alemão não é endossada pelo filósofo francês. Esse seria, inclusive, mais um dos equívocos da apreciação de Escudier, ao afirmar este que, em $A$ memória, a história, o esquecimento, Ricoeur não logrou escapar da dicotomia verdade versus método. Porém, o filósofo disse sempre ter resistido a essa oposição. Aliás, uma das críticas que mais incidem sobre Gadamer dizem respeito, justamente, à sua proposta do acontecer da verdade - seja no apresentar-se da obra de arte, no acontecer da história ou no ontologizar-se da linguagem - não ser um processo que pode ser pareado ao método do conhecimento científico. O problema dessa verdade hermenêutica seria sua difusão, pois não teria um instrumento ou instância crítica própria, ao colocar-se simplesmente como desvelamento do ser da obra de arte, da compreensão histórica e da linguagem (STEIN 1996).

\section{Considerações finais: sobre verdade histórica e método}

Como temos visto ao longo deste artigo, a concepção ricoeuriana da verdade histórica compartilha com a tradição hermenêutica de Heidegger e Gadamer a recusa em pensá-la estritamente como correspondência a uma realidade pré-dada. Todavia, em Ricoeur, a verdade histórica não se contrapõe ao método. Pelo contrário, basta nos lembrarmos de seu apelo à objetividade incompleta e da importância concedida à fase documental da operação historiográfica, à qual o filósofo chega até mesmo a conceder a possibilidade de falseabilidade, nos termos popperianos. O que singulariza sua posição é o esforço de coadunar a empresa metódica da historiografia às reflexões sobre linguagem, narrativa e representância.

Pelo menos desde $A$ metáfora viva, obra gêmea de Tempo e narrativa, o hermeneuta francês tem se mostrado contrário à redução da verdade ao discurso científico descritivo, no qual haveria uma correspondência plena com o real. 
Naquela ocasião, Ricoeur já defendia que mesmo os enunciados metafóricos e o discurso poético apresentam uma referência indireta e mediatizada à experiência. Desse modo, a verdade não fica encerrada somente no discurso literal, mas abre-se à possibilidade de uma verdade metafórica em que há uma tensão no próprio verbo ser, na medida em que no discurso poético até esse verbo é metaforizado. Na metáfora viva, há uma tensão entre o "é" e o "não é"; ela nos possibilita um olhar indireto para a experiência, um ver-como. Essa tensão propicia a geração de novos sentidos para além daqueles obtidos no discurso descritivo, abrindo a realidade para novos horizontes de significação: "Quando o poeta diz: 'a natureza é um templo no qual vivos pilares' o verbo ser não se limita a ligar o predicado 'templo' ao sujeito 'natureza' [...] Pela relação predicativa é redescrito o que é; ela diz que é justamente assim" (RICOUER 2005, p. 377, grifo no original).

Naquele contexto, o filósofo já estava atento para evitar possíveis confusões entre a representação, que refaz a realidade, e a cópia: "representar não é imitar no sentido de assemelhar-se a... ou de copiar. É necessário desfazer cuidadosamente o preconceito segundo o qual representar é imitar por semelhança" (RICOUER 2005, p. 356). Nas interpretações ricoeurianas sobre o discurso ficcional, fica nítida sua distância em relação aos chamados positivistas, que reservam a verdade para a ciência e a falsidade para a ficção. Para Ricoeur, a referência metafórica da ficção possibilita que ela alcance dimensões da experiência inatingíveis pelo discurso descritivo. Por meio da inovação semântica e da potência criativa da linguagem, a poesia e a ficção

104 nos dizem algo novo sobre a realidade: "Pode-se falar em verdade metafórica para designar a intenção 'realista' que se vincula ao poder de redescrição da linguagem poética" (RICOUER 2005, p. 376, grifo nosso).

Se a verdade, particularmente, a histórica, não deve ser reduzida à mera verificação, disso não se deve deduzir um relativismo insensato, que interdita ao conhecimento histórico a construção de algum tipo de verdade. Para além da questão da correspondência e da semelhança, Ricoeur acredita na possibilidade de a historiografia oferecer uma representação fiável do passado. A atenção que ele dirige à dimensão narrativa da história e seu entrecruzamento com a ficção não é empecilho para que, de igual modo, o filósofo confie nos procedimentos metódicos da investigação histórica. Ainda que entremeada pela subjetividade, a história possui um certo tipo de objetividade. Embora não chegue a uma verdade nua, crua e imutável, o saber histórico pode atingir uma verdade no âmbito da probabilidade, o que impulsiona a história a ser constantemente reescrita.

\section{Referências bibliográficas}

ANKERSMIT, Franklin Rudolf. Historia y tropología. Acenso y caída de la metáfora. Trad. Ricardo Martín Rubio Ruiz. México: Fondo de Cultura Económica, 2004.

A escrita da história: a natureza da representação histórica. Trad. Jonathan Menezes et al. Londrina: Eduel, 2012. 
BARTHES, Roland. O discurso da história. In: O rumor da língua. Trad. Mario Laranjeira. São Paulo: Martins Fontes, 2004.

BATISTA, Gustavo Silvano. A questão da representação em Gadamer, Análogos, n. 11 , p. 146-154, 2011.

CERTEAU, Michel de. História e psicanálise entre ciência e ficção. Trad. Guilherme João de Freitas Teixeira. Belo Horizonte: Autêntica Editora, 2012.

CHARTIER, Roger. Defesa e ilustração da noção de representação, Fronteiras, v. 13 , n. 14 , p. 15-29, 2011b.

DOSSE, François. Le moment Ricoeur. Vingtième Siècle Revue d'histoire, $v$. 69, p. 137-152, 2001.

ESCUDIER, Alexandre. Entre épistemologie et ontologie de I'histoire. Le Débat, n. 122, p. 12-23, nov.-dec. 2002.

FALCON, Francisco. História e representação. In: CARDOSO, Ciro Flamarion; MALERBA, Jurandir (org.). Representações: contribuição a um debate transdisciplinar. São Paulo: Papirus, 2000.

GADAMER, Hans-Georg. Verdade e método. 11. ed. Trad. Flávio Paulo Meurer. Petrópolis: Vozes; Bragança Paulista: Editora Universitária São Francisco, 2013.

GAGNEBIN, Jeanne Marie. Do conceito de Darstellung em Walter Benjamin ou verdade e beleza, Kriterion, v. 46, n. 112, p. 183-190, 2005.

A memória, a história, o esquecimento. In: PAULA, Adna Candido; SPERBER, Suzi Frankl (org.). Teoria literária e hermenêutica ricoeuriana: um diálogo possível. Dourados: Ed. UFGD, 2011.

HUMBOLDT, Wilhelm. Sobre a tarefa do historiador (1821). Trad. Pedro Caldas. In: MARTINS, Estevão Rezende (org.). A história pensada: teoria e método na historiografia do século XIX. São Paulo: Contexto, 2010.

LADRIĖRE, Jean. Representação e conhecimento. In: Encyclopædia Universalis. [s.I.]: Encyclopædia Britannica, Inc., [s. d.]. v. 14.

MICHEL, Johann. Paul Ricoeur: une philosophie de l'agir humain. Paris: Éditions du CERF, 2006.

MONGIN, Olivier. Paul Ricoeur. Paris: Seuil, 1994.

PITKIN, Hanna Fenichel. Representação: palavras, instituições e ideias, Lua nova, São Paulo, n. 67, p. 15-47, 2006.

RICOEUR, Paul. Temps et récit. 3 tomes. Paris: Éditions du Seuil, 1991. (Collection Points Essais).

Philosophies critiques de I'histoire: recherche, explication, écriture. In: FLOISTAD, Guttorm (ed.?). Philosophical Problems Today. Boston: Kluwer Academic Publishers, 1994. 
. L'écriture de l'histoire et la representation du passé. Annales. Histoire, Sciences Sociales, n. 4, p. 731-747, 2000a.

. La mémoire, I'histoire, I'oubli. Paris: Éditions du Seuil, 2000b. . Mémoire: approches historiennes, approche philosophique. Le Débat, n. 122 , p. 41-61, nov.-dec. 2002.

. A metáfora viva. 2. ed. Trad. Dion Davi Macedo. São Paulo: Edições Loyola, 2005.

. Percurso do reconhecimento. Trad. Nicolás Nyimi Campanário. São Paulo: Edições Loyola, 2006.

- A marca do passado, Tradução de Breno Mendes e Guilherme da Cruz e Zica. História da Historiografia, n. 10, p. 329-350, 2012.

SILVA, Gilvan Ventura da. História e verdade para além da virada linguística: a contribuição de Frank Ankersmit. História da Historiografia, n. 14, p. 182-186, 2014.

STEIN, Ernildo. Aproximações sobre hermenêutica. Porto Alegre: Editora PUC-Rio, 1996. 